\title{
An Empirical Analysis of the Total Retail Sales of Consumer Goods by Using Time Series Model
}

\author{
Shichang Shen, Xiaoyi Dong \\ School of Mathematics and Statistics, Qinghai Nationalities University, Xining, China \\ Email: 13909785766@163.com
}

How to cite this paper: Shen, S.C. and Dong, X.Y. (2019) An Empirical Analysis of the Total Retail Sales of Consumer Goods by Using Time Series Model. Journal of Mathematical Finance, 9, 175-181. https://doi.org/10.4236/jmf.2019.92009

Received: April 4, 2019

Accepted: May 7, 2019

Published: May 10, 2019

Copyright (c) 2019 by author(s) and Scientific Research Publishing Inc. This work is licensed under the Creative Commons Attribution International License (CC BY 4.0).

http://creativecommons.org/licenses/by/4.0/

\section{cc) (i) Open Access}

\begin{abstract}
With the continuous improvement of living standards, the total amount of social consumer goods in China's economic development has occupied an important position. Its fluctuations can indirectly reflect the demand and purchasing power of commodities, thus affecting the state's macroeconomic regulation and control. This paper selects the total amount of social consumer goods in China from August 2005 to February 2019. Using EViews 7.2 software, this paper makes use of the correlation analysis of sequence fluctuation in econometrics and financial time series, and finds the best fitting EGARCH $(1,1)$ model based on ARMA $(1,0)$ to conduct an empirical analysis of the total amount of social consumer goods in China, and concludes that the total amount of social consumer goods in China has leverage effect.
\end{abstract}

\section{Keywords}

Retail Sales of Consumer Goods, EGARCH Model, Leverage Effect

\section{Introduction}

In recent years, the living standard of residents has been improved, and the increase in consumption has stimulated economic development. However, there are many factors affecting the economic development of China, among which the total retail sales of consumer goods have a huge impact on the economy. Fang Huliu [1] (2009) proposed that the total retail sales of social consumer goods are important data for studying the living standard of residents, the purchasing power of social retail goods and social production. It reflects the improvement of people's material and cultural living standards in a certain period of time and the size of the retail market. Sun Yan and Peng Yangyang (2016) [2] mentioned that the demand of social retail consumer goods has a direct impact on the quantity of consumer goods, and then the country will make corres- 
ponding adjustment to the macro-economy. Finally, the price of consumer goods will also fluctuate. Lin Puren and Hu Xiangfei [3] (2010) summed up the increase of the total retail sales of consumer goods means the increase of demand, which stimulates the economy, further improves the performance of related enterprises and improves residents' income. Conversely, consumer demand will be weak, reducing the rate of economic growth. Miao Tingting [4] (2017) compares the supply and demand of social consumer goods to a circular chain, which affects one ring and interlocks. Peng Bing [5] (2012) mentioned that the research on the total retail sales of consumer goods has become crucial to avoid the situation of oversupply and inflation and promote the continuous development of the economy. Therefore, this paper selects the subject model with better effect, and then finds the EGARCH $(1,1)$ model with a higher fitting degree, and finally makes a correlation analysis on it.

\section{Theoretical Basis}

\subsection{The ARCH Model}

ARCH model was put forward by Engle in 1982 [6] and has been widely used in the financial market.

For the usual regression model, we obtain that:

$$
y_{t}=x_{t}^{\prime} \beta+\varepsilon_{t}
$$

When $\varepsilon_{t}^{2}$ obeys $\operatorname{AR}(\mathrm{q})$ process, we obtain the following:

$$
\varepsilon_{t}^{2}=\alpha_{0}+\alpha_{1} \varepsilon_{t-1}^{2}+\cdots+\alpha_{q} \varepsilon_{t-q}^{2}+\eta_{t}, \quad t=1,2, \cdots
$$

$\eta_{\mathrm{t}}$ is independent and identically distributed, and it satisfies $E\left(\eta_{t}\right)=0$, $D\left(\eta_{t}\right)=\lambda^{2}$, Then, the model can be thought of as autoregressive conditional heteroscedastic model, notes for the ARCH model.

\subsection{The ARCH Effect Test}

To test whether there is ARCH effect, the Lagrange multiplier method, namely LM test, is usually adopted. If the random perturbation term $\varepsilon_{t}$ of the model obeys $\operatorname{ARCH}(q)$, the auxiliary regression equation can be established:

$$
h_{t}=\alpha_{0}+\alpha_{1} \varepsilon_{t-1}^{2}+\cdots+\alpha_{q} \varepsilon_{t-q}^{2}
$$

If the probability of a regression coefficient of 0 is relatively large, there is no $\mathrm{ARCH}$ effect in the sequence; otherwise, the series has an ARCH effect.

\subsection{The EGARCH Model}

The EGARCH model, exponential GARCH model, was developed by Nelson in 1991 [7]. The conditional variance expression of the model is:

$$
\log \left(h_{t}\right)=\alpha_{0}+\sum_{j=1}^{p} \theta_{j} \log \left(h_{t-j}\right)+\sum_{j=1}^{q}\left[\alpha\left|\frac{\varepsilon_{t-i}}{\sqrt{h_{t-i}}}\right|+\varphi_{i} \frac{\varepsilon_{t-i}}{\sqrt{h_{t-i}}}\right]
$$

In this model, the conditional variance is in the form of natural logarithm, 
which means that $h_{t}$ is non-negative, leveraged and exponential. If $\varphi \neq 0$, it means that it is asymmetric. If $\varphi<0$, there is a leverage effect.

\section{Empirical Analysis}

\subsection{Data Preprocessing}

The data were obtained from the Wind database. The Wind database is the most complete and accurate first-rate large-scale financial engineering and financial data warehouse with financial securities as the core in China. And with the help of EViews7.2 [8] [9]. Figure 1 is the trend chart of the total retail sales of consumer goods in China from August 2005 to February 2019. Whether the sequence is stable can be observed or further determined by the unit root test. After observing Figure 1, it is known that the time series data is not stable, and unit root test is conducted further (Table 1).

It can be observed from Figure 1 that there is a trend item in the sequence, and the sequence is preliminarily judged to be unstable. Next, the unit root test is carried out to further determine whether the sequence is stable.

Table 1 is the unit root test of the sequence, and the results show that the unit root statistic $\mathrm{ADF}$ is 1.785051, far higher than the confidence interval of $10 \%, 5 \%$ and $1 \%$, and the probability $P$ value is 0.9997 . It can be judged that the sequence has a unit root, failing the ADF test, indicating that the sequence is unstable.

Because the sequence of total retail sales of social consumer goods is unstable and has trend terms, the differential method is adopted to make it tend to be stable.

By observing Figure 2, it can be seen that the sequence is stable, has a peak value, fluctuates up and down around the value of 0 , and has a state of aggregation, so there may be heteroscedasticity, and unit root test can be conducted further.

According to the data in Table 2, the ADF statistic is far less than the critical value of $1 \%$ significance level, so it can be seen that there is no unit root in the sequence, and the sequence tends to be stable.

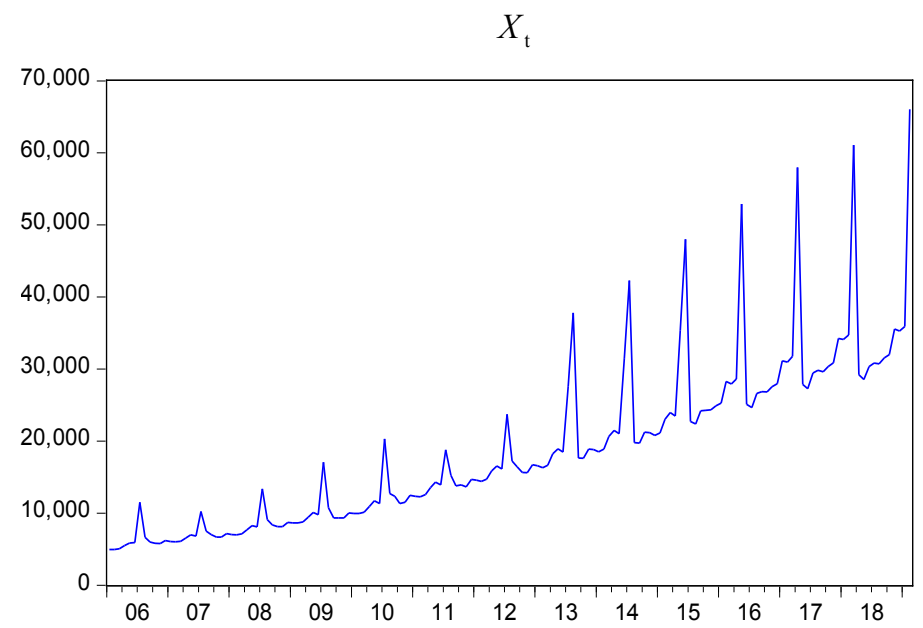

Figure 1. Time series trend diagram. 


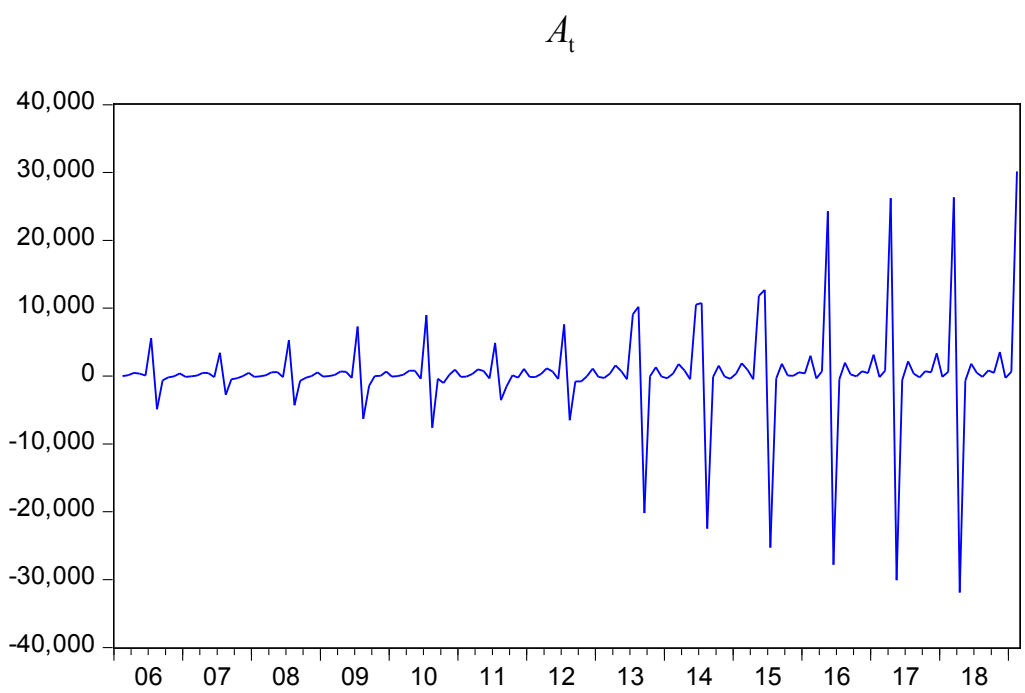

Figure 2. Trend chart of sequence $A_{t}$.

Table 1. ADF test of sequence $X_{t}$.

\begin{tabular}{lccc}
\hline & t-Statistic & Prob. $^{*}$ \\
\hline Augmented Dickey-Fuller test statistic & 1.785051 & 0.9997 \\
Test critical values: & $1 \%$ level & -3.473672 & \\
& $5 \%$ level & -2.880463 & \\
& $10 \%$ level & -2.576939 & \\
\hline
\end{tabular}

Table 2. ADF test of sequence $A_{t}$

\begin{tabular}{cccc}
\hline & & t-Statistic & Prob. $^{*}$ \\
\hline Augmented Dickey-Fuller test statistic & -26.61508 & 0.0000 \\
Test critical values: & $1 \%$ level & -3.473672 & \\
& $5 \%$ level & -2.880463 & \\
& $10 \%$ level & -2.576939 &
\end{tabular}

\subsection{Basic Statistical Characteristics}

By observing the relevant data in the basic statistics Table 3, the skewness is -0.649751 and less than 0 , and it can be judged that there is a phenomenon of left skewness. The kurtosis value of left skewness is 12.77227 , which is much higher than that of the normal distribution.

\subsection{Conditional Heteroscedastic Effect Test}

According to the comparison of relevant parameters of the established model, ARMA $(1,0)$ was finally selected as the main model, and the corresponding parameters were estimated as follows: $A_{t}=-0.373209 A_{t}+\alpha_{t}$. ARCH LM can be used to test whether there is ARCH effect, and residual square correlation graph can also be used to judge. This paper uses the ARCH LM test to determine 
Table 3. Basic statistics for the sequence

\begin{tabular}{ccccccccc}
\hline Mean & Median & Maximum & Minimum & Std.Dve & Skewness & Kurtosis & Jarque-Bera & Prob.* \\
\hline 375.0809 & 95.67500 & 30170.55 & -31888.20 & 7226.546 & -0.649751 & 12.77227 & 656.0046 & 0.000000 \\
\hline
\end{tabular}

whether there is an ARCH effect. First, check whether the second order has the ARCH effect.

Table 4 is the LM test result when the test order $q=2$. From the table, the associated probability of the $\mathrm{F}$ statistic and the $\mathrm{p}$ statistic are both 0.0001 , which indicates the ARCH effect.

It is observed from Table 5 that the probability $\mathrm{P}$ value is less than $1 \%$ when the test order reaches 7th order, and the null hypothesis is rejected. That is, the correlation data of Table 3 and Table 4 can be combined to determine that the residual sequence has a high-order $\mathrm{ARCH}$ effect.

\subsection{The Choice of ARCH Model}

According to the comparison of logarithmic likelihood function, AIC and SC of each model in Table 6, it is found that the AIC value of EGARCH $(1,1)$ model is the minimum, and its logarithmic likelihood function is the maximum. Therefore, it can be judged that the sequence has the best fitting with EGARCH $(1,1)$ model.

According to the relevant statistics of EGARCH $(1,1)$ model, it is found that the $\mathrm{P}$ value of both the leverage coefficient and other coefficients is 0 at the significance level of 0.01 , which can obtain a good fitting effect and further establish the EGARCH $(1,1)$ model:

The mean equation is that: $A_{t}=-0.072308 A_{t-1}+\alpha_{t}$

Variance equation is that:

$$
\log \left(h_{t}^{2}\right)=0.720081+0.972835 \log \left(h_{t-1}^{2}\right)-1.201969 \frac{\left|\alpha_{t-1}\right|}{h_{t-1}}+1.712505 \frac{\alpha_{t-1}}{h_{t-1}}
$$

According to the variance equation, the parametersv $\alpha_{0}=0.720081$ and $\theta_{1}$ $=0.972835$ are both greater than 0 , indicating that the fluctuation is in a forward direction. It was observed that the asymmetric coefficient $\varphi_{1}=-1.201969$ was negative, indicating that the fluctuation of total retail sales of consumer goods was asymmetric and there was leverage effect.

\subsection{The Adaptability Test}

Table 7 gives two test results. It can be seen that the p-value of LM statistic accepts the null hypothesis at the significance level of $1 \%$, and it can be judged that there is no autocorrelation in the residual sequence. Therefore, the EGARCH $(1,1)$ model has the best effect.

\section{Conclusions and Recommendations}

This paper first observed the fluctuation of data and made corresponding processing to make the data tend to be stable. After establishing the subject 
Table 4. Second-order LM test for sequences.

\begin{tabular}{cccc}
\hline F-statistic & 10.24173 & Prob. F (2,158) & 0.0001 \\
\hline Obs $^{\star}$ R-squared & 17.84450 & Prob. Chi-Square (2) & 0.0001 \\
\hline
\end{tabular}

Table 5. Higher-order LM test for sequences.

\begin{tabular}{cccc}
\hline F-statistic & 4.580336 & Prob. F (7,153) & 0.0001 \\
\hline Obs ${ }^{\star}$ R-squared & 27.30282 & Prob. Chi-Square (7) & 0.0003 \\
\hline
\end{tabular}

Table 6. Model identification.

\begin{tabular}{cccc}
\hline & Logarithmic likelihood function & AIC & SC \\
\hline GARCH $(1,1)$ & -1617.742 & 20.14586 & 20.22241 \\
$\operatorname{TARCH}(1,1)$ & -1628.622 & 20.29344 & 20.38914 \\
$\operatorname{EGARCH}(1,1)$ & -1468.280 & 18.30162 & 18.34048 \\
\hline
\end{tabular}

Table 7. ARCH effect test results of sequence residuals.

\begin{tabular}{cccc}
\hline F-statistic & 0.000168 & Prob. F $(1,158)$ & 0.9897 \\
Obs ${ }^{*}$-squared & 0.000170 & Prob. Chi-Square (1) & 0.9896 \\
\hline
\end{tabular}

model, it analyzed the characteristics of related statistics and preliminarily judged that there was ARCH effect in this sequence. Then, it analyzed the extended ARCH model and found that the EGARCH $(1,1)$ model could better reflect the fluctuation of total retail sales of social consumer goods and its fitting was the best.

Further analysis of the EGARCH $(1,1)$ model shows that the leverage coefficient in the model is negative, indicating that the fluctuation of the total retail sales of consumer goods has leverage effect. Therefore, negative returns in the same situation have a more drastic impact on positive returns. Through the above analysis and research on the characteristics of fluctuations, I hope it can be helpful to the development of macro economy.

It can be concluded that we should adjust the supply quantity of retail sales of consumer goods according to the demand. Keep it as balanced as possible. When the purchasing power of residents declines, the price of consumer goods should be lowered to stimulate consumption and drive the development of the whole economy.

On the other hand, when the purchasing power of residents declines, if we just blindly reduce the price of consumer goods is not sustainable, we can only treat the symptoms and not the root cause. Tracing back to the source, we should increase the income of residents and let income drive consumption. At this time, the implementation of state policies is particularly important. Some policies to increase domestic demand should be introduced to increase the income of low-income families, strengthen the construction of people's livelihood, stabilize 
the prices of some consumer goods, and promote the purchasing power of commodities to stimulate stable economic growth.

In addition, there is an error in selecting any model for correlation testing and research. In this paper, based on ARMA model, combined with ARCH model, and errors also exist in the model inspection. In the future, we should improve our knowledge reserve and reduce errors in a large number of reading materials.

\section{Fund}

This work is supported by the National Natural Science Foundation of China (No. 11561056) and Natural Science Foundation of Qinghai (No. 2016-ZJ-914).

\section{Conflicts of Interest}

The authors declare no conflicts of interest regarding the publication of this paper.

\section{References}

[1] Fang, H.L. (2009) Analysis on the Fluctuation Law and Influencing Factors of Total Retail Sales of Consumer Goods. Journal of Shanxi Finance and Economics University, No. 7, 22-28.

[2] Sun, Y. and Peng, Y.Y. (2016) Analysis and Forecast of Total Retail Sales of Consumer Goods in China. Statistics and Decision, No. 18, 90-94.

[3] Lin, P.R. and Hu, X.F. (2010) Forecast Model of Total Retail Sales of Consumer Goods in China. Guangxi Sciences, No. 17, 206-208.

[4] Miao, T.T. (2017) Analysis on Influencing Factors of Retail Sales of Consumer Goods-Empirical Analysis Based on Provincial Panel Data. Times Finance, No. 29, 96-97.

[5] Peng, B. Hu, J.T. and Deng, J. (2012) Empirical Analysis on the Influencing Factors of Total Retail Sales of Consumer Goods in the Yangtze River Delta. Knowledge Economy, No. 12, 93-94.

[6] Engle, R.F. (1982) Autoregressive Conditional Heteroscedaticity with Estimates of the Variance of UK Inflation. Econometrica, 50, 987-1008.

https://doi.org/10.2307/1912773

[7] Nelson, D.B. (1991) Conditional Heteroskedasticity in Asset Returns: A Returns: A New Approach. Econometrica: Journal of the Econometric Society, 59, 347-370. https://doi.org/10.2307/2938260

[8] Yi, D.H. (2008) Data Analysis and Application of EViews. China Renmin University Press, Beijing.

[9] Gao, T.M. (2009) Econometric Analysis Methods and Modeling-EViews Applications and Examples. 2nd Edition, Tsinghua University Press, Beijing. 